\title{
Compressibilities of Long-Chain Normal Hydrocarbons
}

\author{
C. E. Weir and J. D. Hoffman
}

\begin{abstract}
Measurements were made of the compressions of $n-\mathrm{C}_{18} \mathrm{H}_{38}, n-\mathrm{C}_{20} \mathrm{H}_{42}, n-\mathrm{C}_{24} \mathrm{H}_{50}, n-\mathrm{C}_{26} \mathrm{H}_{54}$, $n-\mathrm{C}_{28} \mathrm{H}_{58}$, and $n-\mathrm{C}_{30} \mathrm{H}_{62}$ in the crystalline state at $21^{\circ} \mathrm{C}$. The pressure range used was from 1,000 to 10,000 atmospheres. Within the experimental error, which was fairly large because of the small size of sample, no significant variation of the compression with chain length was observed. The average compression of all the hydrocarbons studied may be represented by the equation
\end{abstract}

$$
-\Delta V / V_{0}=0.1717 \log _{10}(2,500+P)-0.6272 .
$$

The average compressibility of the hydrocarbons extrapolated to 1 atmosphere was calculated to be $29.8 \times 10^{-6} \mathrm{~atm}^{-1}$ at $21^{\circ} \mathrm{C}$.

\section{Introduction}

Considerable interest has been exhibited in the properties of the normal long-chain hydrocarbons, as indicated by numerous reports on studies of these materials. As pointed out earlier $[1],{ }^{1}$ there is need for data on the compressibilities of these materials, the only data available on the crystalline materials appearing to be those of Müller [2] obtained from X-ray measurements on $n-\mathrm{C}_{23} \mathrm{H}_{48}$ and $n-\mathrm{C}_{29} \mathrm{H}_{60}$. Data on the liquids containing between 5 and 10 carbon atoms were reported by Bridgman [3], and Cutler, Schiessler, and Webb [4] have recently reported measurements on $n-\mathrm{C}_{12} \mathrm{H}_{26}, n-\mathrm{C}_{15} \mathrm{H}_{32}$, and $n-\mathrm{C}_{18} \mathrm{H}_{38}$ in the liquid state.

In the present report, data are given for compressions at $21^{\circ} \mathrm{C}$ for some of the crystalline normal hydrocarbons containing between 18 and 30 carbon atoms.

Because of the small amount of each hydrocarbon available, the errors of measurement were necessarily rather large. Accordingly, the present results are of a somewhat exploratory nature, and will probably be subject to slight revision when data on much larger samples are obtained.

\section{Experimental Method}

It was considered desirable to measure the compressibilities at low pressures, i. e., 1 to 1,000 atm, but efforts to do this with the present samples in this pressure range, using piezometric techniques, were unsuccessful. The errors in such measurements were so large as to render the data of dubious value. These errors were probably the result of interfacial effects arising from the fact that the only confining liquids considered inert toward the specimens were water and mercury-both nonwetting liquids. After vacuum impregnation of the specimens with either liquid, unfilled capillary spaces were visible. Presumably these were filled at elevated pressures, thus giving rise to the erratic compressions observed. Attempts to fill the voids permanently at 10,000 atm were unsuccessful because the visible capillaries emptied partially in an irreproducible manner on reduction of the pressure.

\footnotetext{
1 Figures in brackets indicate the literature references at the end of this paper.
}

It was decided, therefore, to measure the compressions at high pressures, where errors arising from void spaces are negligible. The basic techniques and equipment used in such studies have been described earlier [5].

Certain modifications of the procedures were devised to permit study of the small specimens. Each hydrocarbon was fused and recrystallized in a small Pyrex tube, open at one end. The filled tubes were placed, open end down, in a stainless-steel container, open at one end. A steel spring under compression served to hold the open end of the glass tube in contact with the bottom of the steel container. This assembly was evacuated for $1 / 2 \mathrm{hr}$, using a mechanical pump, and the stainless-steel container filled with clean mercury while under vacuum. To minimize danger of contamination of the pressure vessel with mercury, the mercury-filled assembly was placed in a somewhat larger telescoping steel container designed to catch any mercury inadvertently spilled from the inner container. This unit, consisting of telescoping tubes, glass, mercury, spring, and hydrocarbon, represented the compression specimen and was immersed in a light petroleum distillate (Varsol) in the pressure vessel. For a comparison standard the same assembly was used, except that the glass tube contained no hydrocarbon. The comparison material for the hydrocarbon, therefore, consisted of a similar volume of mercury.

Compression data were calculated by means of a generalization of the equation of Adams [6], as follows:

$$
\begin{aligned}
k-k^{\prime}= & \frac{S}{V_{0}}\left\{\Delta L(1+\alpha P)+\Delta l^{\prime} \alpha\left(P-P^{\prime}\right)+\right. \\
& {\left.\left[\nabla l^{\prime}\left(1+\alpha P_{0}\right)+\sum_{n=1}^{n=m-1} \frac{V_{n}^{\prime}-V_{n r}^{\prime}}{S}\right] \frac{k-k_{l}^{\prime}}{1-k_{l}^{\prime}}\right\}+ } \\
& \sum_{n=1}^{n=m-2}\left(k_{n}-k_{n}\right)\left(\frac{V_{n r_{0}}-V_{n_{0}}}{V_{0}}\right) .
\end{aligned}
$$

$P$ denotes pressure in atmospheres and $V$, volume; subscript zero denotes $1 \mathrm{~atm}$, and subscripts $r$ and $l$ refer to measurements made with reference material and pressure-transmitting liquid, respectively. Primes denote the experimental reference pressure 
of $2.000 \mathrm{~atm}$. The compression $k=-\left(V-V_{0}\right) / V_{0}=$ $-\Delta V / V_{0}$ at pressure $P ; k^{\prime}$ is the corresponding compression at $2,000 \mathrm{~atm}$, i. e., $-\left(V^{\prime}-V_{0}\right) / V_{0} . \quad S$ is the area of the bore of the vessel at $1 \mathrm{~atm} ; \alpha$ is the pressure coefficient of this area $(1 / S)(d S / d P) ; \Delta L$ is the difference in travel of the piston at pressure $P$ in the measurements on the reference specimen and the unknown specimen calculated from 2,000 atm; $\Delta l^{\prime}$ is the difference of the positions of the piston at 2,000 atm in the two measurements. The generalization is contained in the two summations, the first being carried out over all $m$ components in the vessel except the pressure-transmitting liquid, and the second for all except the specimen and the liquid.

All components of the compression specimen were weighed and the required volumes calculated from the weights. Known densities of steel and mercury were used, whereas that of the glass was determined by hydrostatic weighing. Volumes of the hydrocarbons were obtained from the weights by use of specific volume-temperature data of Templin [7]. All these data were extrapolated to $21^{\circ} \mathrm{C}$, and some uncertainty (probably not exceeding 1\%) exists in the specific volumes used. The values used were, in cubic centimeters per gram, 1.070 for $\mathrm{C}_{18} \mathrm{H}_{38} ; 1.060$ for $\mathrm{C}_{20} \mathrm{H}_{42}$; and 1.050 for all other specimens. The latter value agrees with a flotation density of $n-\mathrm{C}_{29} \mathrm{H}_{60}$ obtained by Müller [8]. The error introduced through inaccuracies in these values is believed to be less than the precision of the compression measurements.

All glass tubes used were prepared from a single length of tubing, and all were annealed simultaneously. The compression of glass used was that reported by Adams and Gibson [9]. The compression of mercury was also taken from the data of Adams [10] and represents only a slight modification of his published data [6]. The compression of steel did not enter the calculations because the volume of steel was the same in all measurements.

About $1 \mathrm{~cm}_{3}$ of each of the following hydrocarbons was available for study: $n-\mathrm{C}_{18} \mathrm{H}_{38}, n-\mathrm{C}_{20} \mathrm{H}_{42}, n$ $\mathrm{C}_{24} \mathrm{H}_{50}, n-\mathrm{C}_{28} \mathrm{H}_{54}, n-\mathrm{C}_{28} \mathrm{H}_{58}$, and $n-\mathrm{C}_{30} \mathrm{H}_{62}$. The melting points, which were sharp, are given in table 1 .

\section{Results and Discussions}

The results of the compression measurements on the hydrocarbons are given in table 1 . Values of compression, $-\Delta V / V_{0}$, referred to 2,000 atm are tabulated for each 1,000-atm interval; measurements at 1,000 atm appear as negative values because the data are based on the reference point at 2,000 atm. The data at 1,000 atm are less reliable than those at the higher pressures and are not considered in the following discussion. Two independent measurements, obtained at different times, were made on each specimen, and these data are tabulated as runs 1 and 2. The averages of the two measurements on each specimen are also tabulated.

By inspection of the duplicate measurements it is apparent that the errors are large. The increased error [11] is to be expected as the specimen has a volume of only about $1 \mathrm{~cm}^{3}$ out of a total of $25 \mathrm{~cm}^{3}$ of material in the pressure vessel. Ordinarily a 10- to $12-\mathrm{cm}^{3}$ specimen is used. In view of the decreased precision a statistical analysis of the data was carried out. This analysis corroborated a standard deviation of $\pm 0.0040 \mathrm{in}-\Delta V / V_{0}$ and showed that, for a given pressure, no really significant difference exists between the compressions of the different hydrocarbons within experimental error. On this basis the data of table 1 (excluding those taken at $1,000 \mathrm{~atm}$ ) have been averaged, with the results given in the last column of the table. These average data are considered to be representative of all specimens studied. To obtain compressibility data, the average compressions of table 1 were fitted to the Tait equation [12] by means of least squares. The resulting equation,

$$
-\Delta V / V_{0}=0.1717 \log _{10}(2,500+P)-0.6272,
$$

with $P$ in atmospheres, reproduces the average compression data within \pm 0.0005 , which is well within the experimental error. The fit of eq 2 with the experimental data as averaged at each pressure is shown in figure 1. The corresponding values of the

TABLE 1. Compressions of normal hydrccarbons

Compression, $-\Delta V / V_{0}$

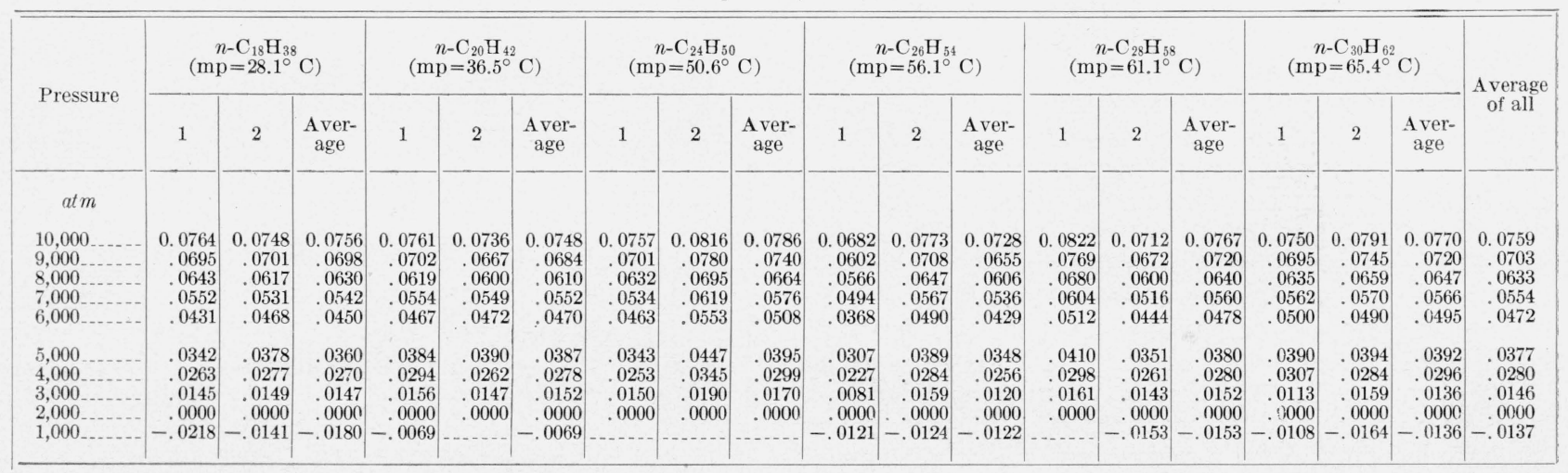




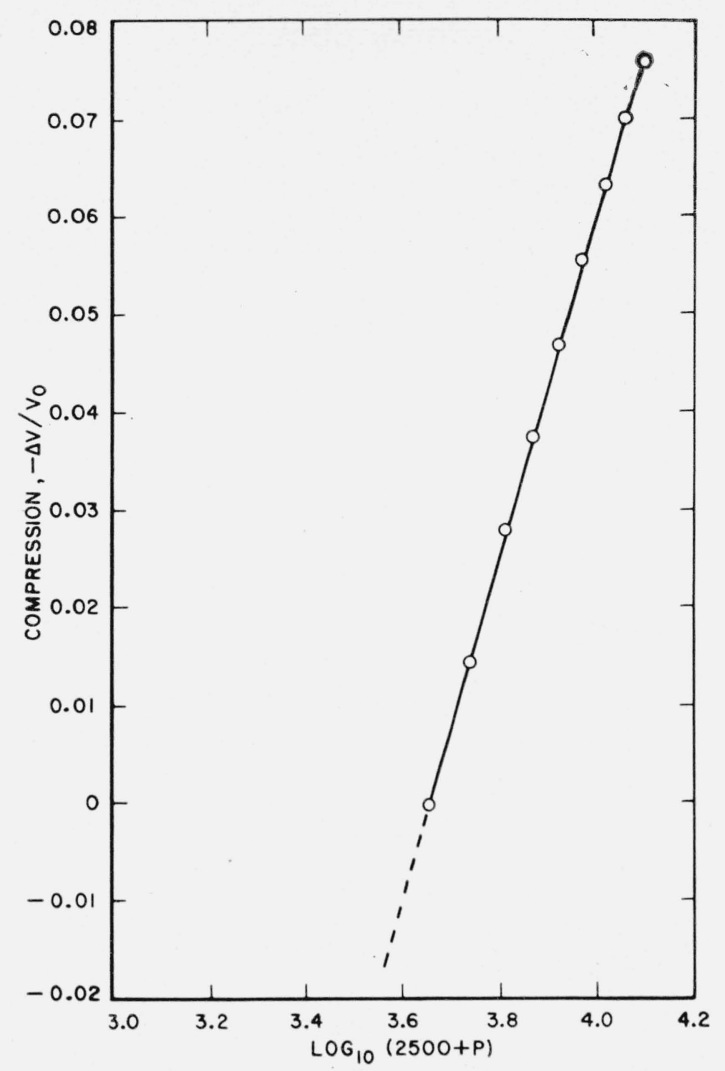

Figure 1. Plot of Tait equation for normal hydrocarbon.

compressibility at the various pressures are given in figure 2 .

It has been noted by Gibson [12] that the Tait equation reproduces both volume and compressibility data on many materials with great accuracy over a wide pressure range (see also [4]). Of immediate interest is the fact that this equation, although empirical, has been used very successfully in extrapolating from low to high pressures. The reverse process is used here, as data are desired at low pressures. From the derivative of eq 2 it is found that the compressibility is given by the equation

$$
-\frac{d V}{V_{0} d P}=\frac{0.1717}{2.303(2,500+P)} .
$$

If $P \ll 2,500 \mathrm{~atm}$, the volume compressibility is found to be $29.8 \times 10^{-6} \mathrm{~atm}^{-1}$. Statistical analysis of the data indicates that the standard deviation in the value is $0.4 \times 10^{-6} \mathrm{~atm}^{-1}$. The true value may, of course, lie outside these limits.

It is interesting to compare the present results with those of Müller [2], who measured the change in $\mathrm{X}$-ray spacings with pressure for the odd-carbon compounds $n-\mathrm{C}_{23} \mathrm{H}_{48}$ and $n-\mathrm{C}_{29} \mathrm{H}_{60}$. In making this comparison, it should be remembered that the even- and odd-carbon hydrocarbons have different crystal structures at room temperature, so that close agree-

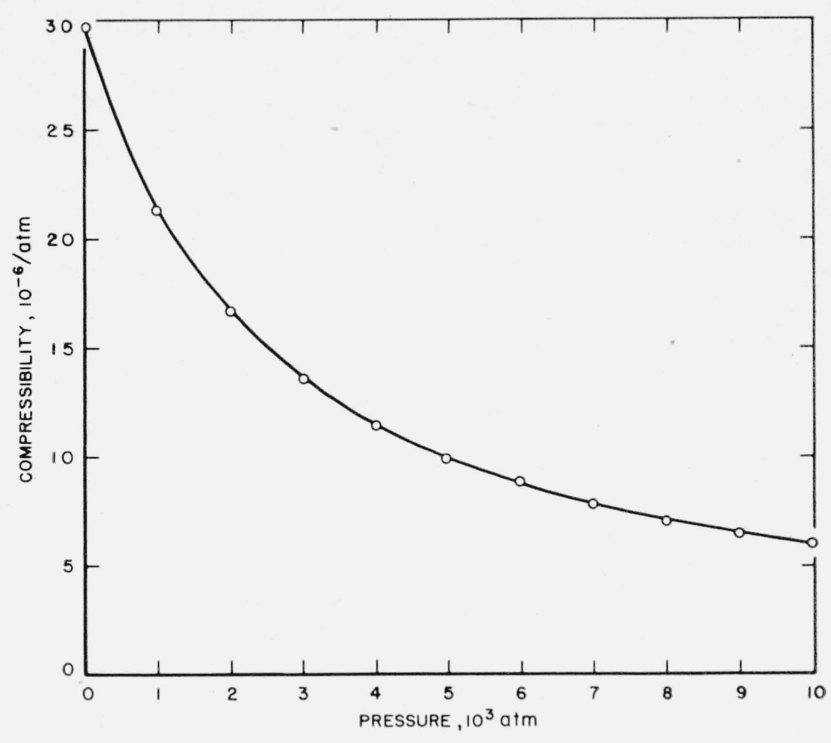

FIGURE 2. Average compressibitity-pressure relationship in normal hydrocarbon.

ment of the compressibility values is not necessarily to be expected. At room temperature the oddcarbon compounds from $n-\mathrm{C}_{21} \mathrm{H}_{44}$ to $n-\mathrm{C}_{29} \mathrm{H}_{60}$ are orthorhombic, whereas the even-carbon compounds from $n-\mathrm{C}_{18} \mathrm{H}_{38}$ through $n-\mathrm{C}_{24} \mathrm{H}_{50}$ are triclinic; $n-\mathrm{C}_{28} \mathrm{H}_{58}$ and $n-\mathrm{C}_{30} \mathrm{H}_{62}$ are monoclinic [13]. Both the monoclinic and triclinic forms appear simultaneously in $n-\mathrm{C}_{26} \mathrm{H}_{54}[1,13]$. Using Müller's finding [2] that the compressibility is essentially a two-dimensional effect, ${ }^{2}$ the linear compressibility values quoted in Müller's paper are equivalent to volume compressibilities of $21 \times 10^{-6} \mathrm{~atm}^{-1}$ for $n-\mathrm{C}_{23} \mathrm{H}_{48}$, and $5.5 \times 10^{-6}$ $\mathrm{atm}^{-1}$ for $n-\mathrm{C}_{29} \mathrm{H}_{60}$. These values represent the average compressibility at $500 \mathrm{~atm}$; our value at the same pressure for the even-carbon compounds is $25.5 \times 10^{-6} \mathrm{~atm}^{-1}$.

The effects arising at chain ends lead to the expectation that the compressibility should decrease slightly with increasing chain length in the normal hydrocarbons. Bridgman's data on the liquid hydrocarbons [3] up to $n-\mathrm{C}_{10} \mathrm{H}_{22}$ show this effect. The data of Cutler, Schiessler, and Webb [4] on $n-\mathrm{C}_{12} \mathrm{H}_{26}$, $n-\mathrm{C}_{15} \mathrm{H}_{32}$, and $n-\mathrm{C}_{18} \mathrm{H}_{38}$ in the liquid state also show a slight decrease of compressibility with length of chain. However, in the latter study it is clear that the effect decreases with increasing chain length and pressure, as would be expected. Bridgman [14] has reported data on polyethylene of three different average molecular weights in the range 14,000 to 38,000 that show no significant effect of molecular weight on compressibility, and verify the belief that the effect of chain ends on compressibility becomes negligible as the chain length increases in this partially amorphous and partially crystalline (monoclinic) polymer. The fact that no effect of chain length on compressibility is shown by the present

2 The changes with pressure of the X-ray spacings found by Müller were stated to be almost entirely a result of the hydrocarbon chains moving closer together laterally. 
data on the crystalline hydrocarbons implies that such an effect is smaller than the experimental error of the measurements. Similarly, there does not appear to be any large difference in the compressibilities of the triclinic and monoclinic forms of the even-carbon hydrocarbons because the results for materials with 18 to 24 carbon atoms do not differ greatly from those for materials with 28 and 30 carbon atoms per molecule.

The authors are indebted to J. Mandel for advice in connection with the statistical analyses of the experimental data.

Washington, September 7, 1955.

\section{References}

[1] J. D. Hoffman and Buelah F. Decker, J. Phys. Chem. 5\%, 520 (1953).

[2] A. Müller, Proc. Roy. Soc. (London) [A] 178, 227 (1941).

[3] P. W. Bridgman, The physies of high pressure (G. Bell \& Sons, Ltd., London, 1949).

[4] W. G. Cutler, R. W. Schiessler, and W. Webb, Bul. Am. Phys. Soc. [3] 30, 38 (1955).

[5] C. E. Weir, J. Research NBS 45, 468 (1950) RP2160.

[6] L. H. Adams, J. Am. Chem. Soc. 53, 3769 (1931).

[7] P. R. Templin, M. S. Thesis, University of Pittsburgh (1954).

[8] A. Müller, Proc. Roy. Soc. (London) [A] 120, 437 (1928).

[9] L. H. Adams and R. E. Gibson, J. Wash. Acad. Sci. 21, 381 (1931).

[10] L. H. Adams (private communication).

[11] C. E. Weir, J. Research NBS 52, 247 (1954) RP2496.

[12] R. E. Gibson, J. Am. Chem Soc. 59, 1521 (1937).

[13] A. A. Schaerer, C. J. Busso, A. E. Smith, and L. B. Skinner, J. Am. Chem. Soc. $7 \%, 2017$ (1955).

[14] P. W. Bridgman, Proc. Am. Acad. Arts Sci. 76, 55 (1948) 